\title{
Path Loss Estimation for Some Korek-Telecom Sites Operating at (1.8) GHz and (2.1) GHz for Urban and Suburban Area in Erbil City
}

\author{
Sattar Othman Hasan*, Sevan Siyyah Abdullah \\ Salahaddin University-Erbil, Physics Department, College of Education, Erbil, 44001, Iraq
}

\author{
A R T I C L E I N F O \\ Article history: \\ Received: 01 August, 2020 \\ Accepted: 29 September, 2020 \\ Online: 12 October, 2020
}

Keywords:

Radio wave propagation

Path loss

Derive test

Signal strength

\begin{abstract}
A B S T R A C T
This investigation deals with the identification of the suitable empirical models for predicting radio wave propagation path losses in Erbil city of Kurdistan region in Iraq. For this purpose, two sites of Korek Telecom operating at $1800 \mathrm{MHz}$ and $2100 \mathrm{MHz}$ have been selected at urban and sub-urban environments in the city and seven different empirical path loss model named free space model, ECC-33, Stanford Interim University (SUI), Optimized Cost-231, Okumura-Hata, Egli, and Ericson models are tested against experimentally measured path loss values. The path loss was measured experimentally using Sony Ericson handset with complete required equipment and the results are compared to that predicted by each of the mentioned empirical models. The results which have been analyzed through the identification of Root Mean Square Error value achieved by each model revealed that the Optimized Cost-231 and Ericson model provide lowest Root Mean Square Error values. They provide RMSE values of 9.21, 9.38 and 1.58 and 4.12 at operating frequency of $1800 \mathrm{MHz}$, while at frequency $2100 \mathrm{MHz}$ they gave 7.28, 6.07, 11.86 and 7.54, for sub-urban and urban areas, respectively. Therefore, it was concluded that the Optimized Cost-231 followed by Ericson model would be more reliable and best candidate for use in planning and designing network communication in the urban and suburban areas in the investigated area.
\end{abstract}

\section{Introduction}

In Kurdistan region of Iraq, the access to Global System for Mobile Communication (GSM) has become most active industry in 2005 to the present day. The numbers of network service providers continue to increase, but the quality of their services is poor due to several factors. The investigation and identification of the possible factors and proper solutions through scientific findings became necessary towards solving problems faced by the customers [1]. The wireless communication systems are a process by which the electromagnetic waves propagated from one location to another transferring data or information without any wire [2]. With constant increase in the field of GSM for mobile communication, the need for providing high quality data and reliable network services be an urgent issue for user services demands. Generally, development in the wireless communications systems has now become down due to focusing

\footnotetext{
*Corresponding Author: Sattar Othman Hasan, sattar.hasan@su.edu.krd
}

technological advancements. Therefore, in order to obtain reliable and suitable coverage area for wireless communication, high quality with high capacity networks and accurate estimation of signal strength must be taken into consideration $[1,2]$.

The signal strength of radio wave decreases when propagating between the transmitter and/or receiver due to many factors such as, reflection, diffraction, scattering, path distance, environments (i.e. urban, suburban or rural), height of the transmitter and receiver antennas and absorption by the object of the environment as well as operation frequencies [3]. Such reduction in the power strength of the signal is known as radio wave propagation path loss. Mathematically, it is expressed as the ratio between the transmitted power $P_{t}$ to received power $P_{r}$ as given by [4]:

$$
\mathrm{PL}(\mathrm{dB})=10 \log \frac{\mathrm{P}_{t}}{\mathrm{P}_{r}}
$$

The models presented in the literature for path loss calculations play an important role in planning and designing of any wireless communication systems. They are based on a series of 
mathematical equations that are used for predicting radio wave propagation signal strength in a definite environment [5]. The proper estimation of radio frequency path losses leads to the development of efficient network planning to operate at high quality with high capacity network.

In recent years, different propagation path loss models were presented to help the wireless systems to provide high quality and service delivery. These models cannot be generalized to all environments, since each of which may applicable for a specific environment and at a certain operational frequency [6]. The main objective of this research is to identify the model environment suitable for predicting radio wave propagation path loss in Erbil city of Kurdistan region in Iraq. The outcome may be assisting the wireless communication companies to plans for the best Global System for Mobile Communication (GSM) networks in the city under consideration.

For this purpose, two of the Korek telecom cellular sites operating at frequencies $1.8 \mathrm{GHz}$ and $2.1 \mathrm{GHz}$ are selected and investigated with the use of seven familiar empirical path loss models. The selected sites are located at Sharawany(sub-urban) and Bakhtiary(urban) which are two districts area in the Erbil city of different location and have different building organization. The procedure of the measured and calculated results is described in the following sections.

\section{Empirical models}

As previously mentioned, there were different proposed models considered under different circumstances and positions for estimating radio wave path loss. This fact implies that the reliability of any model that predict path loss accurately, based on the terrain in which it is developed.

The most familiar empirical models that are available for estimating radio wave propagation path loss in different environment are, free space, ECC-33, Stanford Interim University (SUI), Optimized Cost-231, Okumura-Hata, Egli and Ericson models. The mathematical equations and their application ranges for each of these models that have been considered in this study are described briefly in the following subsections individually.

\subsection{Path loss model for free space}

For free-space path loss model, the lost in signal strength is specified only by the frequency operation and separation distance between transmitter and/or receiver without taking into account the signal reflection or absorption by object surrounding the medium. The theoretical derivation of the free space path loss formula is given by [7]:

$$
\mathrm{PL}_{\mathrm{FSPL}}=32.45+20 \log _{10}(d)+20 \log _{10}\left(f_{c}\right)
$$

\subsection{Okumura-Hata model}

The Okumura-Hata model is one of the most familiar models which is very applicable for path loss prediction. Generally, most of path loss empirical models are consolidate form of the Okumura model which can be used at frequencies up to $3 \mathrm{GHz}$. This model is applicable for a separation ranges of about $100 \mathrm{~km}$ between transmitter and receiver and for the receiver height in between $3 \mathrm{~m}$ to $10 \mathrm{~m}$. The path loss expression in this model has different form according to the environment of wave propagation and are as follows [8]:

Rural environment (dB)

$$
\begin{aligned}
& \mathrm{PL}(\mathrm{dB})=69.55+26.16 \log _{10}\left(f_{c}\right)-13.82 \log _{10}\left(h_{t}\right)+ \\
& \left(44.9-6.55 \log _{10}\left(h_{t}\right)\right) \log _{10}(d)-4.78\left(\log _{10}\left(f_{c}\right)\right)^{2} \\
& \quad+18.33 \log _{10}\left(f_{c}\right)+40.94
\end{aligned}
$$

Suburban areas path loss $(d B)$

$$
\begin{aligned}
\mathrm{PL}(\mathrm{dB}) & =69.55+26.16 \log _{10}\left(f_{c}\right)-13.82 \log _{10}\left(h_{t}\right) \\
& +\left(44.9-6.55 \log _{10}\left(h_{t}\right)\right) \log _{10}(\mathrm{~d}) \\
& -2\left(\log _{10} \frac{f_{c}}{28}\right)^{2}+10.8-\mathrm{E}
\end{aligned}
$$

Urban area path loss $(d B)$

$$
\begin{aligned}
\mathrm{PL}(\mathrm{dB})= & 69.55+26.16 \log _{10}\left(f_{c}\right)-13.82 \log _{10}\left(h_{t}\right)+ \\
& \left(44.9-6.55 \log _{10}\left(h_{t}\right)\right) \log _{10}(\mathrm{~d})-\mathrm{E}
\end{aligned}
$$

where, $\quad \mathrm{E}=3.2\left[\log _{10}\left(11.75 h_{r}\right)\right]^{2}-4.97$

In all considered models, the following parameter symbols have the same representation and are as follows [8]-[9]:

$h_{t}$ : transmitter antenna height in $\mathrm{m}$,

$h_{r}$ : receiver antenna height in $\mathrm{m}$,

$d$ : distance between base station and mobile receiver in $\mathrm{km}$,

$f_{c}$ : operating frequency in $\mathrm{MHz}$.

\subsection{Optimization Cost-231}

The equation of the path loss proposed by this model is an extension of COST-231 by introducing a correction factor through the least square fitting process of the measured data by [8]:

$$
\begin{gathered}
\mathrm{PL}(\mathrm{dB})=41.42+33.9 \log _{10}\left(f_{c}\right)-13.82 \log _{10}\left(h_{t}\right)- \\
\mathrm{a}\left(h_{r}\right)+\left[44.9-6.55 \log _{10}\left(h_{r}\right)\right] \log _{10}(d)+\mathrm{C}_{\mathrm{K}}
\end{gathered}
$$

The correction factor $\mathrm{Ck}=0 \mathrm{~dB}$ for suburban and $\mathrm{Ck}=3 \mathrm{~dB}$ for urban environments. the expression for $\mathrm{a}\left(h_{r}\right)$, for sub-urban and rural environments, is:

$$
\mathrm{a}\left(h_{r}\right)=\left(1.11 \log \left(f_{c}\right)-0.7\right) h_{r}-\left(1.56 \log \left(f_{c}\right)-0.8\right)
$$

While a $\left(h_{r}\right)$ in urban area for $f_{c} \geq 400 \mathrm{MHz}$ is:

$$
\mathrm{a}\left(h_{r}\right)=\left(3.20\left[\log 11.75 h_{r}\right] 2\right)-4.97
$$

\subsection{Ecc-33 model receiver}

The ECC-33 path loss model is proposed by Electronic Communication Committee (ECC) which is considered as an appropriate model for the UHF frequency band. This model derived on the bases of the extrapolation to the measurement path loss data by Okumura model. The general path loss representation formula for this model is [10]: 
$P L(d B)=A_{f}+A_{m}-G_{t}-G_{r}$

where, $\mathrm{G}_{t}$ and $\mathrm{G}_{r}$, are transmitter and receiver antenna height gain factor, respectively, while $\left(A_{f}\right)$ represent attenuation due free space $[\mathrm{dB}]$ and $\left(\mathrm{A}_{\mathrm{m}}\right)$ is accounted for median path loss $[\mathrm{dB}]$. They are mathematically defined as given by [11]:

$$
\begin{aligned}
& \mathrm{A}_{\mathrm{f}}=92.4+ 20 \log _{10}(d)+20 \log _{10}\left(f_{c}\right) \\
& \mathrm{A}_{\mathrm{m}}= 20.41+9.83 \log _{10}(d)+7.894 \log _{10}\left(f_{c}\right)+ \\
& 9.56\left[\log _{10}\left(f_{c}\right)\right]^{2}
\end{aligned}
$$

$\mathrm{G}_{t}=\log _{10}\left(\frac{h_{t}}{200}\right)\left\{13.958+5.8\left[\log _{10}(d)\right]^{2}\right\}$

$\mathrm{G}_{r}=\left[42.57+13.7 \log _{10}\left(f_{c}\right)\right]\left[\log _{10}\left(h_{r}\right)-0.585\right]$

for rural and medium city,

$\mathrm{G}_{r}=0.759\left(h_{r}\right)-1.862$ for large city

\subsection{Stanford University Interim (SUI) model}

The SUI model extended the Hata model by modification of some parameters in order to be applied to a frequency bands up to 3 $\mathrm{GHz}$. In this model, the base station antenna height allows to vary from $10 \mathrm{~m}$ to $80 \mathrm{~m}$ and the receiver height can take values between $2 \mathrm{~m}$ to $20 \mathrm{~m}$. This model proposed different mathematical formula for different types of environment, such as dense urban, hilly regions and rural with moderate vegetation areas. Here, the basic path loss expression for SUI model with its correction factors are presented which given by [12]:

$$
\mathrm{PL}(\mathrm{dB})=\alpha+10 \beta \log \left(\frac{d}{d_{r}}\right)+\mathrm{Y}_{f}+\mathrm{Y}_{h}+\mathrm{s} \text { for } d>d_{r}
$$

where, $\left(d_{r}\right)$ is the reference distance $\left(d_{r}=100 \mathrm{~m}\right),(d)$ is the separation distance between transmitter and receiver antenna in meters. The parameter $(\beta)$ is called path loss exponent factor and is determined through the equation below:

$$
\beta=\mathrm{a}-\mathrm{b} h_{t}+\frac{c}{h_{t}}
$$

Both $\left(\mathrm{Y}_{f}\right)$ and $\left(\mathrm{Y}_{h}\right)$ are the frequency correction factor and correction factor for receiving antenna height, respectively, and they are given by [13]-[14] as:

$$
\mathrm{Y}_{f}=6.0 \log _{10}\left(\frac{f_{c}}{2000}\right)
$$

For sub-urban and urban city $Y_{h}$ is expressed as:

$$
\mathrm{Y}_{h}=-10.8 \log _{10}\left(\frac{h_{r}}{2000}\right)
$$

While for rural area or small size city is given as:

$$
Y_{h}=-20.0 \log _{10}\left(\frac{h_{r}}{2000}\right)
$$

The shadowing factor is represented by parameter ( $\mathrm{s}$ ) and its values is in between $8.2 \mathrm{~dB}$ and $10.6 \mathrm{~dB}$ [14]. The value of the constants $\mathrm{a}, \mathrm{b}$ and $\mathrm{c}$ which depend upon the environment types are given in Table 1. Finally, the parameter $(\alpha)$ is known as the intercept factor and is expressed as [10-15]:

$$
\alpha=20 \log _{10}\left(\frac{4 \pi d_{r}}{\lambda}\right)
$$

where, $(\lambda)$ is the wavelength in $(m)$,

Table 1: Different terrains and their parameters for SUI model [14-15].

\begin{tabular}{|c|c|c|c|}
\hline Model Parameter & Urban & Sub-urban & Rural \\
\hline $\mathrm{S}$ & 10.6 & 9.6 & 8.2 \\
\hline $\mathrm{c}(\mathrm{m})$ & 12.6 & 17.1 & 20.0 \\
\hline $\mathrm{b}\left(\mathrm{m}^{-1}\right)$ & 0.0075 & 0.0065 & 0.0050 \\
\hline $\mathrm{a}$ & 4.6 & 4.0 & 3.6 \\
\hline
\end{tabular}

\subsection{Egli model}

The Egli model is a reliable model for use in network communication systems for a frequency bands from $3 \mathrm{MHz}$ to $3 \mathrm{GHz}$ and is usually applicable when a fixed antenna and receiver mobile antenna are line of sight LOS [16]. The Egli path loss model is an empirical model based on real data measurement and it mathematically presented by [16]-[18] as:

$$
\begin{array}{ll}
\mathrm{PL}(\mathrm{dB})=20 \log _{10}\left(f_{c}\right)+\mathrm{P}_{l}+76.3 & h_{r} \leq 10 \\
\mathrm{PL}(\mathrm{dB})=20 \log _{10}\left(f_{c}\right)+\mathrm{P}_{l}+83.9 & h_{r}>10
\end{array}
$$

where,

$$
\mathrm{P}_{l}=40 \log _{10}(d)-20 \log _{10}\left(h_{t}\right)-10 \log _{10}\left(h_{r}\right)
$$

\subsection{Ericson model}

The Ericson company provided a software by their network designing engineers for predicting radio wave path losses so is called Ericson model. This model also stands on the modification of Okumura-Hata model according to the wave propagation environment. The mathematical formula given by this model is expressed as [19].

$$
\begin{aligned}
\mathrm{PL}(\mathrm{dB})=\mathrm{a}_{\mathrm{o}} & +\mathrm{a}_{1} \log (d)+\mathrm{a}_{2} \log \left(h_{t}\right)+\mathrm{a}_{3} \log \left(h_{t}\right) \cdot \log (d) \\
& -3.2\left[\log \left(11.75 h_{r}\right)^{2}\right]+\mathrm{g}\left(f_{c}\right)
\end{aligned}
$$

where:

$$
\mathrm{g}\left(f_{c}\right)=44.49 \log \left(f_{c}\right)-4.78\left[\log \left(f_{c}\right)\right]^{2}
$$

The values of $\left(a_{0}, a_{1}, a_{2}\right.$ and $\left.a_{3}\right)$ for different environment types are given in Table 2 [11-19].

Table 2: Value of parameters $\left(\mathrm{a}_{0}, \mathrm{a}_{1}, \mathrm{a}_{2}\right.$ and $\left.\mathrm{a}_{3}\right)$ for different environment area

\begin{tabular}{|c|c|c|c|c|}
\hline Environment & $\mathbf{a}_{\mathbf{3}}$ & $\mathbf{a}_{\mathbf{2}}$ & $\mathbf{a}_{\mathbf{1}}$ & $\mathbf{a}_{\mathbf{o}}$ \\
\hline Rural & 0.1 & 12.0 & 100.6 & 45.95 \\
\hline Suburban & 0.1 & 12.0 & 68.93 & 43.20 \\
\hline Urban & 0.1 & 12.0 & 30.20 & 36.20 \\
\hline
\end{tabular}




\section{Materials and method}

Erbil town is the capital city of Kurdistan region of Iraq. It is an urban city characterized by sites located near moderate and tall mountains, residential and commercials buildings as well as small size industries and large offices. The GSM service providers in the town are Asia cell, Korek Tel, and Zain operating at $900 \mathrm{MHz}$, $1800 \mathrm{MHz}$ and $2100 \mathrm{MHz}$. For this study, two of Korek Tel towers at two different location Sharawany and Bakhtiari in the city are selected and the methodology for the measurement is employed. Sharawany is regarded as a sub-urban territory due to low population and flat building construction houses which are surrounded by parks and open parking areas. Bakhtiari is considered as an urban region because it consists of many high building towers built of concrete block material and of high dense population markets.

The measurement devices which consists of a laptop with Test Mobile Systems (TEMS) investigator software and all other required accessories installed and arranged inside the deriving car. The received signal strength is measured as the vehicle moves away from the fixed transmitted tower at every $50 \mathrm{~m}$ using the Ericsson handset and transferred to the TEMS log file in the laptop. The numbers of data were between 10 to 20 reading for each coverage area. A GPS monitor was attached and used to record coordinates of the sites under investigation and tracking distances covered. The height of the BTS antennas located at Sharawany and Bakhtiari are $20 \mathrm{~m}$ and $28 \mathrm{~m}$, respectively, while the mobile station height is kept at $1.5 \mathrm{~m}$. The car which is used for moving away from the base station was driven at a speed of about $30 \mathrm{~km} / \mathrm{hr}$ while the TEMS recorded the received power. Figures 1 show the log files representation of the signal strength level tracking by the GPS indicator during the drive test for suburban and urban areas, respectively.

The frequency was set to $1800 \mathrm{MHz}$ for the first test case and then the process is repeated at $2100 \mathrm{MHz}$ for the second test case at both mentioned base station towers. The measured received signal power is transferred to the TEMS logs file in the laptop by using Ericsson mobile phones. Measurement were carried out in November 2019 and the field data collection was done with the test drive Korek telecom technique team in the mentioned cells areas. The coordinate of the tower sites with its heights, transmitting power as well as its location and antennas type are presented in Table 3.

Table 3: Simulation parameters of the selected Korek tower site

\begin{tabular}{|l|l|l|}
\hline Antenna type & K-80010307 & K-800010485 \\
\hline Tower location & Sharawany-A & Bakhteari \\
\hline Operating frequency $(f)$ & $1.8 \mathrm{MHz}$ and $2.1 \mathrm{MHz}$ \\
\hline Mobile antenna height $\left(h_{r}\right)$ & \multicolumn{2}{|c|}{$1.5 \mathrm{~m}$} \\
\hline Base station height $\left(h_{t}\right)$ & $20 \mathrm{~m}$ & $28 \mathrm{~m}$ \\
\hline Base station power $\left(P_{t}\right)$ & \multicolumn{2}{|c|}{$43 \mathrm{~dB}_{\mathrm{m}}$} \\
\hline
\end{tabular}

The measured received signal strength at different distances with the corresponding measured path loss in the mentioned regions and at both operating frequencies are presented in Figures 2 and Figure 3, respectively. These figures indicate that the signal strength power decreases with increasing distance from the towers and also decrease with increasing operation frequencies regarded in this investigation.

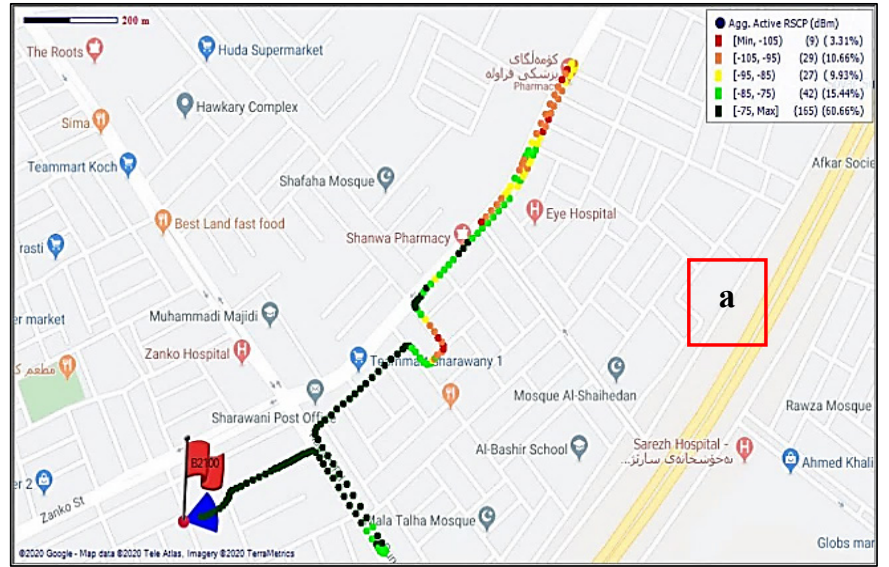

(a)

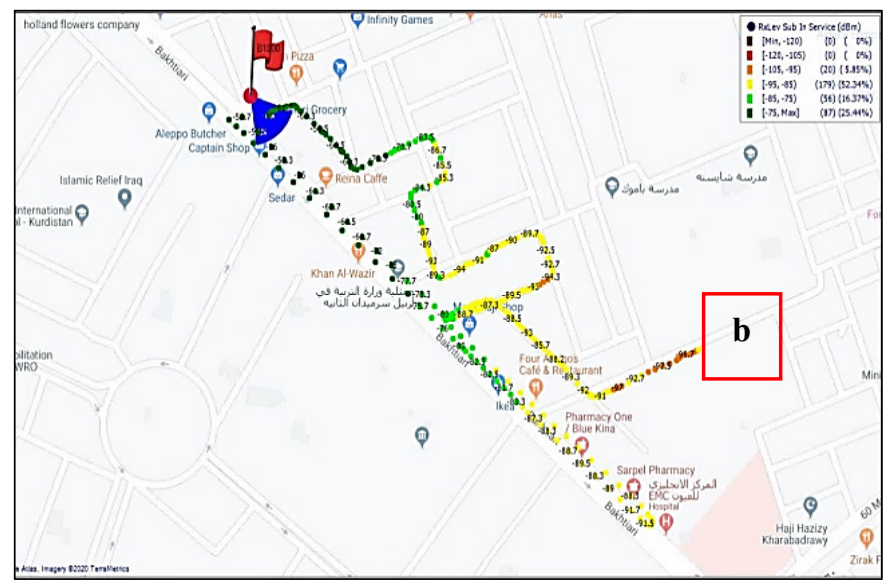

(b)

Figure 1: $\log$ files showing the received signal level distribution for (a) suburban and (b) urban environments.
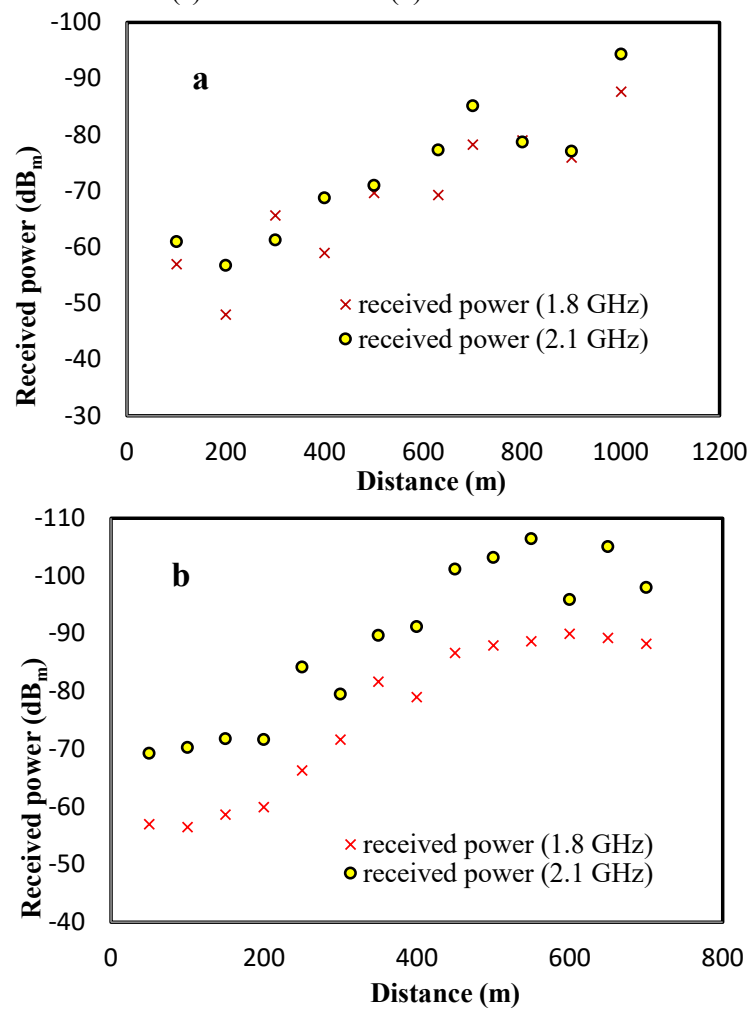

Figure 2: Measured received signal versus distance for (a) suburban \& (b) urban environments. 

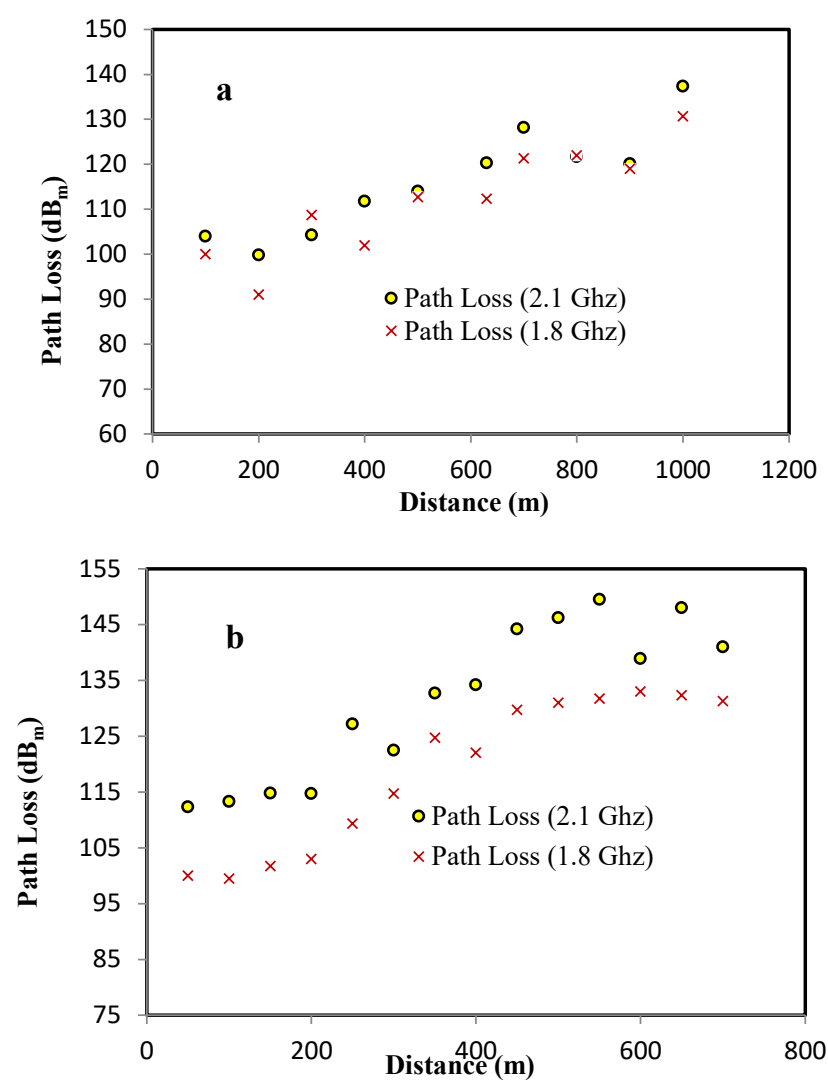

Figure 3: Measured path loss versus distance for (a) suburban \& (b) urban environments.

\section{Results and discussion}

In order to verify which empirical path loss model is reliable and valid for mobile telecommunication systems in Erbil city, the measured path loss data have been compared to the most familiar empirical path loss models. The models that were selected for this study are free space model, ECC-33, SUI, Optimized Cost-231, Okumura-Hata, Egli and Ericson models. The selection of these models is based on the fact that they take various parameters into consideration for the estimation of radio wave propagation path loss, such as separation between antenna base station and mobile receiver, antenna heights and type of environment. Moreover, they are applicable for a frequency ranging from $1800 \mathrm{MHz}$ to $2100 \mathrm{MHz}$.

The path loss values for the mentioned prediction models are calculated using equations $2,4,5,6,9,15,21$ and 24 . The results of the path loss computation with the use of these models and those measured practically are simulated on a MATLAB code developed for this study are shown together on the same path loss distribution graph. The calculated results for suburban are shown in Figures 4 and for urban area are presented in Figure 5 at both operation frequencies of $1800 \mathrm{MHz}$ and $2100 \mathrm{MHz}$, respectively.

Generally, these figures indicate that the path loss increases with distance away from the base station due to many diffractions through obstacle in environment of propagation. The obtained results for sub-urban areas are shown in Figures 4, implies that the Okamura-Hata, ECC-33 and Egli models are overestimated while, SUI with FSPL models provide an underestimated radio wave propagation path loss value.

In addition, the Optimum Cost-231 and Ericson models seem to estimate the radio wave propagation path loss values as close as to that obtained experimentally at both operational frequencies. Moreover, the computed results for urban environment as presented in Figures 5, indicate that the FSPL and SUI models are underestimated while the other models provide values approximately close to that measured experimentally except path loss values predicted by Egli model. Egli model in both environment and at both operational frequencies provide path loss values so far from the measured path loss data.

It can also be observed from these figures that the FSPL model extremely under estimated the path loss in both environments. This may be due to the topography of the sites as the state is hilly in terrain. However, it is also evident from the plots that the optimized Cost-231 model and Ericson model gave a close estimation values for path losses in this environment.

For further confirmation, comparison between measured path loss and the predicted path loss models are also done through the calculation of root mean square value RMSE and mean absolute percentage error MAPE. These two parameters which identify the reliable model accurately for a given environment is obtained by using the following mathematical formula as given by [13] as:

$$
\begin{gathered}
R M S E=\frac{1}{n} \sum_{t=1}^{n} \sqrt{\left(P_{m t}-P_{R t}\right)^{2}} \\
M A P E=\frac{1}{n} \sum_{t=1}^{n}\left|\frac{\left(P_{m t}-P_{R t}\right)}{P_{m t}}\right| \times 100 \%
\end{gathered}
$$

where: $P_{m t}$ is the value of measured data, $P_{R t}$ is the value of predicted path loss values and $(n)$ is the number of data points [20].
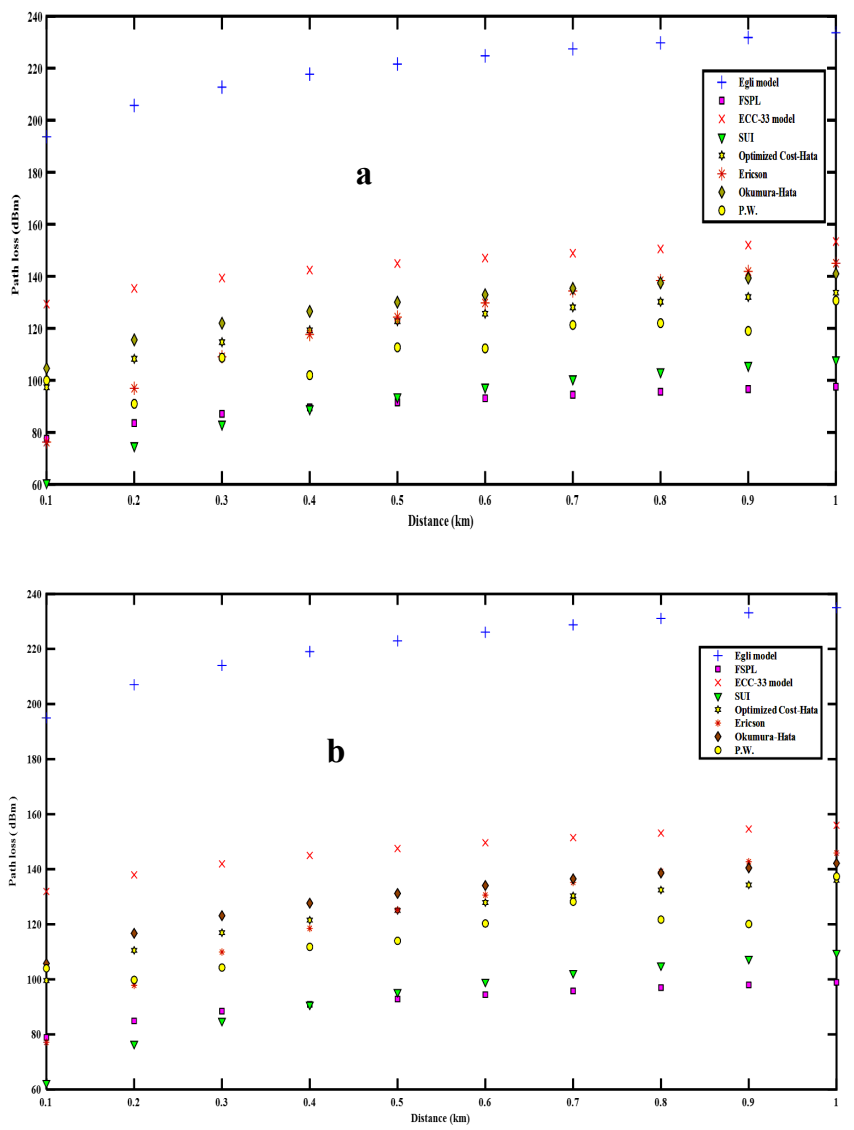

Figure 4: Comparison between measured and different empirical path loss model calculation versus distance from the transmitting tower antenna in suburban area operating at: (a) $1.8 \mathrm{GHz} \&$ (b) $2.1 \mathrm{GHz}$ 

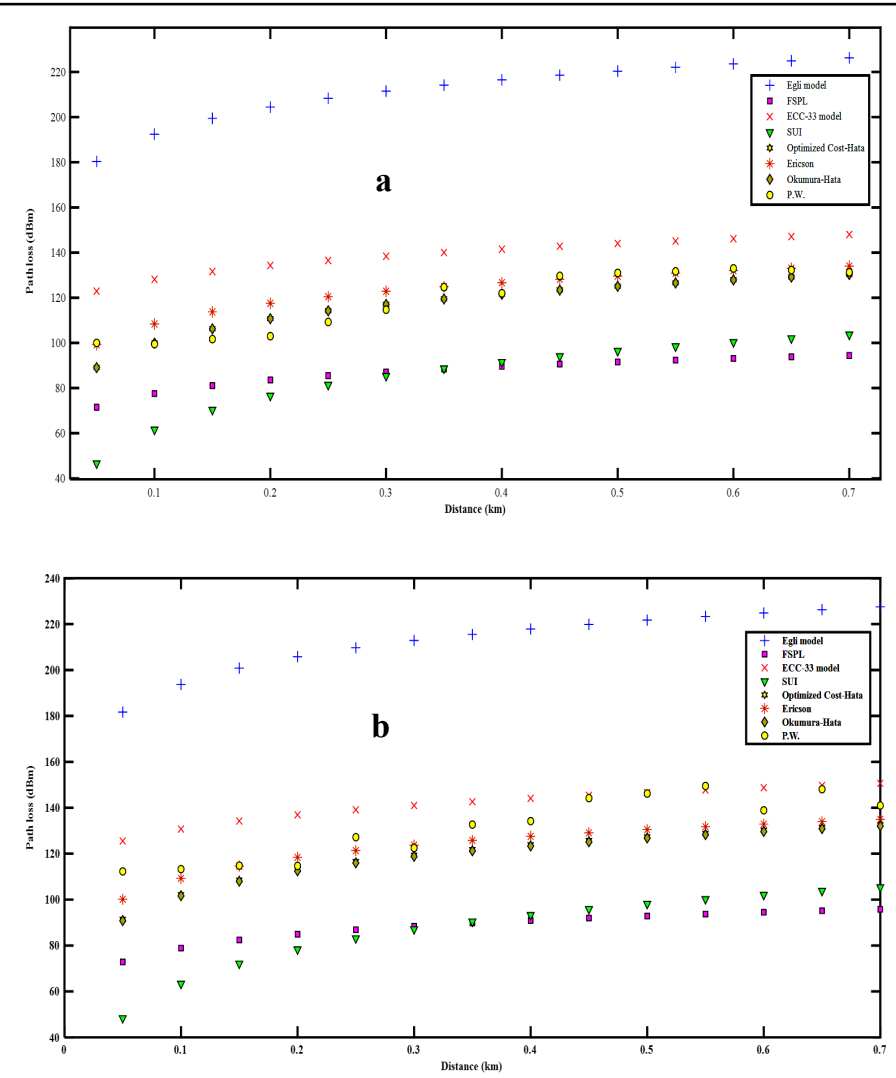

Figure 5: Comparison between measured and different empirical path loss model calculation versus distance from the transmitting tower antenna in urban area operating at: (a) $1.8 \mathrm{GHz} \&$ (b) $2.1 \mathrm{GHz}$

The computed results for each of these two parameters and in both environments with the operation frequencies $1800 \mathrm{MHz}$ and 2100 $\mathrm{MHz}$ are presented in Tables 4 and 5, respectively. Generally, the results as depicted in in these two tables reveals that the Optimized Cost-231 followed by Ericson models provide better performance in predicting radio wave path losses compared to the other empirical models considered in this investigation. Since, the Optimized Cost-231 models gives the lowest RMSE 9.21 and 1.58 with MAPE 0.76 and 0.09 at $1800 \mathrm{MHz}$ frequency bands and RMSE 7.28 and 11.86 with MAPE 0.59 and 0.70 at $2100 \mathrm{MHz}$ frequency bands in sub-urban and urban area, respectively.

Table 4: Performance of different path loss models in both environment at frequency of $1.8 \mathrm{GHz}$.

\begin{tabular}{|l|c|c|c|c|}
\hline \multirow{2}{*}{ Model } & \multicolumn{2}{|c|}{ Sub-Urban } & \multicolumn{2}{c|}{ Urban } \\
\cline { 2 - 5 } & RMSE & MAPE & RMSE & MAPE \\
\hline FS-Model & 38.70 & 2.55 & 28.31 & 1.35 \\
\hline ECC-33 & 31.38 & 2.18 & 16.75 & 0.87 \\
\hline SUI & 20.35 & 2.09 & 33.32 & 2.62 \\
\hline Opt. Cost231 & 9.21 & 0.76 & 1.58 & 0.09 \\
\hline Okumura- & 15.75 & 1.23 & 14.73 & 0.77 \\
\hline Egli & 107.89 & 4.89 & 92.77 & 3.12 \\
\hline Ericson & 9.387 & 0.90 & 4.12 & 0.22 \\
\hline
\end{tabular}

In addition, it is evident from these tables that the Egli, SUI and FSPL models are not reliable for predicting radio wave path loss in our environment under consideration due to their high RMSE and MAPE values in both environment and at both operation frequencies. Therefore, the Optimized Cost-231 model followed by Ericson model can be used successfully to the network planning and designing problems in the sub-urban and urban areas of the Erbil city.

Table 5: Performance of different Path loss models in both environment at frequency of $2.1 \mathrm{GHz}$.

\begin{tabular}{|l|c|c|c|c|}
\hline \multirow{2}{*}{\multicolumn{1}{c|}{ Model }} & \multicolumn{2}{c|}{ Sub-Urban } & \multicolumn{2}{c|}{ Urban } \\
\cline { 2 - 5 } & RMSE & MAPE & RMSE & MAPE \\
\hline FS-Model & 35.85 & 2.34 & 17.10 & 0.80 \\
\hline ECC-33 & 30.71 & 2.09 & 7.72 & 0.39 \\
\hline SUI & 22.80 & 2.31 & 44.13 & 3.43 \\
\hline Opt. Cost231 & 7.28 & 0.59 & 11.86 & 0.70 \\
\hline Okumura-Hata & 12.82 & 0.99 & 3.93 & 0.20 \\
\hline Egli & 105.04 & 4.74 & 81.56 & 2.72 \\
\hline Ericson & 6.07 & 0.63 & 7.54 & 0.44 \\
\hline
\end{tabular}

\section{Conclusions}

In this study, the performance of different empirical model has been tested for predicting radio wave propagation path loss for urban and sub-urban areas in Erbil city. It is obviously observed that the Egli and ECC-33 models are overestimated while both FSPL and SUI models are underestimated path loss values in both environment under consideration. In addition, the results also demonstrated that the path loss values evaluated by Optimized Cost-231 and Ericson models are in good agreement with those measured experimentally. Since, the MAPE values provided by Optimized Cost-213 are $(0.76,0.09,0.59$ and 0.70$)$ and that obtained by Ericson are $(0.90,0.22,0.63$ and 0.44$)$ at respective operation frequencies for sub-urban and urban environment, respectively.

Generally, as a results of these calculation one can concluded that the estimation of radio wave propagation path loss value in urban and suburban environment is best estimated by these two models especially Optimized Cost-231 model in the city under consideration as a whole.

\section{Conflict of Interest}

The authors declare no conflict of interest.

\section{Acknowledgment}

The authors would like to thank the Korek Telecommunication Company for all the cooperation.

\section{References}

[1] D. A. Tonga,"Path loss propagation model prediction for GSM mobile networks in nigeria", First International Conference on Information Technology, Communications and Computing (ICITCC 2017), 24December-2017, doi: 10.5281/zenodo.1130791.

[2] Z. Nadir, "Seasonal pathloss modeling at $900 \mathrm{Mhz}$ for Oman", International Conference on Telecommunication Technology and Applications, 5, 2011, https://www.researchgate.net/publication/228895216_Seasonal Pathloss_Modeling_at_900MHz_for_OMAN.

[3] P. K. Sharma , "Comparative study of path loss models depends on various parameters", International Journal of Engineering Science and Technology, 3(6), 4683-4690, 2011, doi: 10.24018/ejers.2017.2.5.346.

[4] V. Armoogum., K.M.S Soyjaudah., N Mohamudally. and T. Fogarty , " Propagation models and their applications in digital television broadcast network design and implementation", March 2010, doi: 10.5772/8471. 
[5] P. Pathania, P. Kumar and B. S. Rana, " Performance evaluation of different path loss models for broadcasting applications", American Journal of Engineering Research (Ajer), 3(4), 335-342, 2014, https://www.researchgate. net/publication/293326766_Performance_Evaluation_of_different_Path_L oss Models for Broadcasting applications

[6] K. A. Akpado and A. Adewale," Pathloss prediction for a typical mobile communication system in Nigeria using empirical models", International Jounal of Computer Networks and Wireless Communications (Ijcnwc), 3(2), 2013, https://www.researchgate.net/publication/241688188_Pathloss _Prediction_for_a_typical_mobile_communication_system_in_Nigeria_usi $\overline{\mathrm{n} g}$ _empirical_models

[7] I. B. Oluwafemi and O. J. Femi-Jemilohun, " Suburban area path loss propagation prediction and optimization at 900 and $1800 \mathrm{MHz}$, Journal of Engineering and Applied Sciences, 13(9), 2521-2529, 2018, doi: $10.36478 /$ jeasci.2018.2521.2529.

[8] A. O. Oyubu, " A comparative study of free space and Okumura-Hata models in GSM signal path loss prediction in south-south Nigeria", International Journal of Advencements in Research and Technology, 5(5), 34-44,2016. https://www.semanticscholar.org/paper/a-comparative-study-of-free-spaceand-Okumura-Hata/e1a80e192f191ed861bff040b3e390326db26480.

[9] P. O. Omolaye, G. A. Igwue and G. A. Akpakwu, " Okumura-Hata: a perfect model for driving route UHF investigation", American Journal of Engineering Research, 4(9), 139-147, 2015. https: //issuu.com/ajer. Research /docs/t04901390147.

[10] K. Ayyappan and P. Dananjayan," Propagation model for highway in mobile communication system", Ubiquitous Computing and Communication Journal, 3(4), 61-66, 2010, https://citeseerx.ist.psu.edu/viewdoc/download? doi $=10.1 .1 .548 .5163 \&$ rep $=$ rep $1 \&$ type $=$ pdf.

[11] J. Chebil, A. K. Lawas and M. D. Rafiqul Islam, " Comparison between measured and predicted path loss for mobile communication in Malasia", World Applied Sciences Journal, 21, 123-128, 2013, doi: 10.5829 /idosi.wasj.2013.21.mae.99936.

[12] I. Khan and S. A. Kamboh, " Performance analysis of various path loss models for wireless network in different environments", International Journal of Engineering and Advanced Technology, 2, 161-165, 2012, https: //www.researchgate.net/publication/235459463_Performance_Analysis_of Various Path Loss Models for_Wireless Network in Different Enviro nments.

[13] S. I. Popoola and O. F. Oseni ," Empirical path loss models for GSM network deployment in Makurdi, Nigeria", International Refereed Journal of Engineering and Science, 3, 85-94, 2014.

https://www.researchgate.net/publication/264036911_Empirical_Path_Loss Models for GSM Network Deployment in Makurdi Nigeria.

[14] $\bar{N}$. Shabbir and M. T. Sadiq," Comparison of radio propagation models for long term evaluation (LTE) network", International Journal of Next Generation Networks (Ijngn), 3(3), 27-41 2011, doi: 10.5121/ijngn.2011.3303.

[15] N. M. Shebani, A. E. Mohammed , M. A. Mosbah and Y. A. Hassan, "Simulation and analysis of path loss models for WiMax communication system", Research Gate, 692-703, 2013.

https://www.researchgate.net/publication/269222079 Simulation and Ana lysis_of_Path_Loss_Models_for_WiMax_Communication_System.

[16] A. O. Akende, F. A. Semire and Z. K. Adeyemo, "Performance analysis and optimization of Cost231-Hata model for mobile communication in Nigeria" International Journal of Computer Applications, , 173(6), 2017, doi: 10.5120/ijca2017915310.

[17] A. L. Imoize and T. E. Ogunfuwa,"Propagation measurements of a 4G LTE network in Lagoon Environment", Nigerian Journal of Technological Development, 16(1), 1-9, 2018, doi: 10.4314/njtd.v16i1.1.

[18] H. Oudira, L. Djouane and M. Garah , "Optimization of suitable propagation model for mobile communication in different area", International Journal of Information Science \& Technology, 3(3), 10-19, 2019.

https://www.researchgate.net/publication/332687459_Optimization_of_Sui table Propagation Model for Mobile Communication in Different Area

[19] Y. Zakaria, J. Hosek and J. Misurec, "Path loss measurements for wireless communication in urban and rural environments", American Journal of Engineering and Applied Sciences, 94-99, 2015, doi: 10.3844/ajeassp.2015.94.99.

[20] N. Fesseha, Fine-tuning of Cost-231 Hata path loss model for LTE network: the case of 4 Kilo area, M.Sc. Thesis, Addis Ababa University, Ethiopia, 2018. 